\title{
IMPLEMENTASI NETWORK ADDRESS TRANSLATION (NAT) MENGGUNAKAN KERIO CONTROL VERSI 7.4.1 DI PUSAT PENELITIAN BIOTEKNOLOGI - LIPI
}

\author{
Tutang ${ }^{1 *}$, Ario Tutuko², Khoirur Rosyidin ${ }^{3}$ \\ ${ }^{123}$ Pranata Komputer, Pusat Peneitian Bioteknologi LIPI \\ *Korespondensi: tutang@msn.com
}

\begin{abstract}
Biotechnology Research Center as an institution engaged in the research, the need for data and updated information is an absolute thing. This requirement can be met one of them is the use of information technology either by using the internet. With the increasing number of Internet users in Biotechnology Research Center and order for all users who are members of the Local Area Network (LAN) can utilize the internet needed a good network management. While, during the network management Indonesian Institute of Sciences (LIPI), under the supervision of the Joint Network Team (TGJ - LIPI ) only provide one local IP segment which is limited to only 250 users. While number of internet users in Biotechnology Research Center and more than that number will continue to grow. To overcome these problems, then the LAN network at the Research Center for Biotechnology service facility utilizes Network Address Translation (NAT) contained in Kerio Control software version 7.4.1. The subject of this article is limited to the implementation and configuration of NAT using Kerio Control 7.4.1 version. From these results, we concluded that the implementation of NAT helps all users in the network LAN Biotechnology Research Center get Public IP, so that it can connect to the internet properly.
\end{abstract}

\begin{abstract}
ABSTRAK
Pusat Penelitian Bioteknologi sebagai lembaga yang berkecimpung dalam penelitian, kebutuhan data dan informasi ter-update adalah suatu hal yang mutlak. Kebutuhan ini dapat terpenuhi, salah satunya dengan menggunakan teknologi informasi internet. Dengan semakin bertambahnya jumlah pengguna internet di Puslit Bioteknologi dan agar semua pengguna yang tergabung dalam Local Area Network (LAN) dapat memanfaatkan internet maka dibutuhkan pengelolaan jaringan yang baik. Sementara itu, selama ini pengelolaan jaringan Lembaga Ilmu Pengetahuan Indonesia (LIPI), berada di bawah pengawasan Tim Gabungan Jaringan (TGJ - LIPI) hanya menyediakan 1 segmen IP lokal yang terbatas hanya 250 pengguna. Sedangkan, jumlah pengguna internet di Puslit Bioteknologi lebih dari angka tersebut dan akan terus bertambah. Untuk mengatasi masalah tersebut, maka jaringan LAN pada Puslit Bioteknologi memanfaatkan fasilitas servis Network Address Translation (NAT) yang terdapat di dalam software Kerio Control versi 7.4.1. Pokok bahasan dalam tulisan ini dibatasi pada implementasi dan konfigurasi NAT menggunakan Kerio Control versi 7.4.1. Dari hasil penelitian ini, diperoleh kesimpulan bahwa implementasi NAT membantu semua pengguna di jaringan LAN Puslit Bioteknologi mendapatkan IP publik sehingga dapat terhubung ke internet dengan baik.
\end{abstract}

Keywords: Public IP; Kerio Control 7.4.1; Local Area Network; Network Address Translation

\section{PENDAHULUAN}

Pusat Penelitian (Puslit) Bioteknologi adalah satuan kerja di bawah Lembaga Ilmu Pengetahuan Indonesia (LIPI) yang merupakan lembaga penelitian di bidang bioteknologi. Sebagai lembaga yang berkecimpung dalam penelitian, kebutuhan akan data dan informasi ter-update adalah suatu hal yang mutlak. Hal ini penting dalam rangka menunjang pekerjaan untuk memperkaya data dan informasi terkait bidang penelitian serta mendapatkan literatur, baik buku, jurnal ilmiah, e-book, e-magazine, maupun jurnal online. Kebutuhan ini dapat terpenuhi, salah satunya dengan menggunakan teknologi informasi.

Kemajuan yang pesat di bidang teknologi informasi, tentunya patut disyukuri. Teknologi yang 
dimaksud adalah internet dan jaringan komputer global yang mendukungnya. Internet merupakan salah satu sarana yang dapat mempermudah dalam pengaksesan data dan informasi. Penyebaran data dan informasi lebih cepat melalui dunia maya, seperti portal, website, e-journal, e-book, dan jurnal online. Keberadaan internet mutlak adanya dan tidak bisa tergantikan. Namun, arus lalu lintas data dan internet yang lancar membutuhkan infrastruktur yang baik. Agar akses internet dapat dimanfaatkan oleh seluruh pengguna di lingkungan perusahaan atau instansi pemerintah maka diperlukan pengelolaan jaringan yang baik. Selain itu, diperlukan koneksi yang stabil juga dibutuhkan Internet Protocol (IP) address agar pengguna dapat mengakses internet dengan memanfaatkan IP lokal tanpa masalah dan hambatan.

Pengelolaan jaringan komputer di Puslit Bioteknologi tidak berdiri sendiri, tetapi institusi ini mendapatkan akses internet dari jaringan pusat LIPI yang dikelola oleh TGJ - LIPI. Dari Jaringan pusat LIPI membagi kepada satuan - satuan kerjanya, baik satuan kerja yang berada di Jakarta, Bandung, Cibinong, Jawa Tengah, Jawa Timur, Ambon, maupun satuan kerja lainnya. Sedangkan, Puslit Bioteknologi mendapatkan pembagian IP lokal yang beralamat di 192.168.51.1, segmen 51. IP lokal ini hanya dapat mengakomodasi pengguna yang tidak lebih dari 250 host komputer. Sedangkan pengguna jaringan internet di Puslit Bioteknologi tersebut samakin banyak seiring jumlah pegawai yang meningkat. Ketersediaan alamat IP terbatas sehingga jaringan LAN Puslit Bioteknologi membutuhkan pengelolaan penggunaannya sejalan dengan perkembangan jumlah host komputer dan alat yang terhubung ke jaringan komputer. Untuk itu, sejak beberapa tahun terakhir, IP 192.168.51.1 sampai dengan 192.168.51.20 yang dikelola oleh Puslit Bioteknologi digunakan untuk alamat device, sedangkan IP 192.168.51.200 sampai dengan 192.168.51.220 digunakan sebagai alamat web server, mail server, dan sebagainya. Jadi, praktis IP yang bisa digunakan adalah antara 192.168.51.11 sampai dengan IP 192.168.51.199, sedangkan jumlah pengguna lebih dari 400 orang, ditambah lagi device lain, seperti router dan smartphone, dengan sisa IP tersebut sudah tidak memungkinkan lagi.

Melihat kenyataan tersebut, salah satu solusinya adalah dibutuhkan suatu mekanisme yang dapat menghemat IP tersebut. Logika sederhana, untuk penghematan IP publik adalah share suatu nomor IP ke beberapa client IP lainnya, dan mekanisme tersebut disediakan oleh NAT (Cohen, 2009). Kerio Control versi 7.4.1 menyediakan fasilitas NAT yang dapat diimplementasikan di Puslit Bioteknologi. Dengan mekanisme NAT yang disediakan Kerio Control, jaringan LAN Puslit Bioteknologi dapat terhubung ke jaringan internet walaupun hanya memiliki satu IP yang dikelola oleh LIPI.

Sebagaimana diketahui bahwa teknologi NAT saat ini secara luas digunakan, baik oleh perusahaan besar, perusahaan kecil, maupun pengguna rumahan. Hal tersebut disebabkan karena mereka tidak memiliki alamat IP yang cukup untuk memberikan satu alamat IP publik untuk setiap perangkat yang terhubung ke internet. Melalui mekanisne NAT memungkinkan beberapa komputer untuk berbagi alamat IP publik. NAT adalah solusi praktis untuk diterapkan pada jarigan yang memanfaatkan IPv4 (Zhen-hua and Zhang-yi, 2010).

Saat ini, jaringan komputer masih banyak yang menggunakan IPv4 walaupun masih sering menghadapi masalah distribusi IP yang tidak memadai. Dengan demikian, NAT merupakan solusi untuk diterapkan. Meskipun IPv6 mungkin bisa memecahkan masalah di masa depan, tetapi saat ini layanan IP masih menggunakan IPv4 sehingga masih memerlukan sistem firewall sederhana, seperti NAT. Selain itu, mentransfer semua komponen jaringan dari IPv4 ke IPv6 masih terhitung sangat mahal dan membutuhkan waktu yang lama untuk berkembang (Yao; Hwang; Yeh, 2014).

Tujuan utama dari implementasi NAT di Puslit Bioteknologi adalah memberikan IP yang dibutuhkan dalam jaringan lokal sehingga semua pengguna dapat memanfaatkan akses jaringan intranet, 
internet, dan membatasi jumlah IP yang digunakan oleh pengguna. Kajian ini ini dibatasi pada implementasi dan konfigurasi NAT menggunakan Kerio Control versi 7.4.1 serta manfaatnya bagi pengguna di Puslit Bioteknologi.

\section{TINJAUAN PUSTAKA}

\subsection{Internet Protocol}

Internet Protocol (IP) adalah protokol yang mengatur routing dari pentransmisian melewati jaringan antara pengirim dan penerima. IP dapat dikatakan sebagai perantara komunikasi antarkomputer dengan menggunakan IP address sebagai suatu identitas dari jaringan atau komputer. IP address terdiri dari 32 bit dan terbagi menjadi dua bagian, yaitu network ID dan host ID (Rachman dan Yugianto, 2008).

IP versi 4 (IPv4) sudah ada sejak awal 1980-an dan versi ini banyak digunakan sampai saat ini. IP adalah salah satu protokol utama dalam TCP/IP. Dalam model OSI, protokol bekerja pada lapisan network dan fungsi utama dari protokol adalah mengidentifikasi host berdasarkan alamat logis mereka untuk rute data antara mereka melalui jaringan. Alamat logis dari sebuah host dalam jaringan adalah alamat IP dan IPv4 skema pengalamatan yang telah digunakan untuk sementara waktu sekarang dalam mengidentifikasi host dalam jaringan, sistem ini didasarkan pada 32-bit alamat logis (Babatunde dan Al-Debagy, 2014).

Beberapa aturan dasar dalam menentukan network ID dan host ID yang dapat digunakan ketika akan membangun sebuah jaringan LAN, yaitu: a) Network ID 127.0.0.1 tidak dapat digunakan, karena merupakan default yang digunakan untuk keperluan menunjuk dirinya sendiri (loop-back); b) host ID tidak boleh di-set 1 (ex. 126.255.255.255), karena akan diartikan sebagai alamat broadcast (ID broadcast merupakan alamat yang mewakili seluruh anggota pada jaringan); c) network ID dan host ID tidak boleh sama dengan 0 (ex. 0.0.0.0), karena IP address dengan host ID 0 diartikan sebagai alamat network (alamat yang digunakan untuk menunjuk suatu jaringan, dan tidak menunjuk suatu host); d) host ID harus unik dalam suatu network, dan dalam suatu network tidak boleh ada dua host dengan host ID yang sama.

\subsection{Network Address Translation}

Network Address Translation (NAT) adalah suatu metode untuk menghubungkan lebih dari satu komputer ke jaringan internet dengan menggunakan satu alamat IP publik (Grang and Gupta, 2013). Metode NAT banyak digunakan di seluruh dunia termasuk di Indonesia. Pada dasarnya semua jenis NAT beroperasi dengan cara client - server. Dalam hal ini, klien di zona internal yang memulai permintaan untuk memperoleh sumber daya dari server di zona internet publik (Masoud, 2013). Di sini semua klien akan mendapatkan alamat IP lokal yang diberikan oleh komputer server. Dengan mekanisme NAT terbatasnya IP publik tidak menjadi masalah.

Salah satu syarat untuk menghubugkan komputer ke jaringan internet adalah dengan menggunakan IP publik. Melalui NAT memungkinkan beberapa node untuk berbagi satu atau lebih alamat IP publik. Gateway NAT berada pada batas jaringan lokal dan publik dan memodifikasi alamat IP lokal dan port dari paket yang diperuntukkan untuk jaringan publik. Paket IP yang dibundel dengan IPSec, seperti AH dan ESP secara intrinsik dimaksudkan untuk melindungi integritas dari paket IP (termasuk sumber dan tujuan alamat) dari perubahan atau gangguan karena peran 
fundamental NAT gateway untuk memodifikasi alamat IP dalam header paket, IPSec, dan NAT memiliki ketidakcocokan intrinsik (Ahmad and Yaacob, 2012).

NAT bekerja dengan mengalihkan suatu paket data dari suatu alamat IP ke alamat IP lainnya. Ketika suatu paket dialihkan, NAT akan mengingat dari mana asal paket dan kemana tujuan paket tersebut. Apabila paket kembali, NAT akan mengirimkannya ke alamat asal atau dengan kata lain host hanya akan menerima paket yang dikirim atau yang dimintanya sehingga komunikasi dapat berjalan dengan baik.

Jaringan komputer LAN yang menggunakan NAT disebut dengan NATted Network. Sebagai contoh, di MikroTik NAT digunakan untuk komunikasi internal dan komunikasi eksternal maksudnya pengalihan data dapat dilakukan untuk paket yang berasal dari jaringan NATted (internal) ke jaringan luar eksternal atau dari jaringan luar menuju jaringan NATted. Hal tersebut sering disebut dengan komunikasi dua arah dari dan ke jaringan NATted atau internal. Untuk mengetahui mekanisme bagaimana sebuah NAT bekerja, Gambar 1 di bawah ini merupakan contoh jaringan komputer LAN yang dihubungkan dengan gateway dan terkoneksi ke jaringan ingternet (Basuki, 2003).

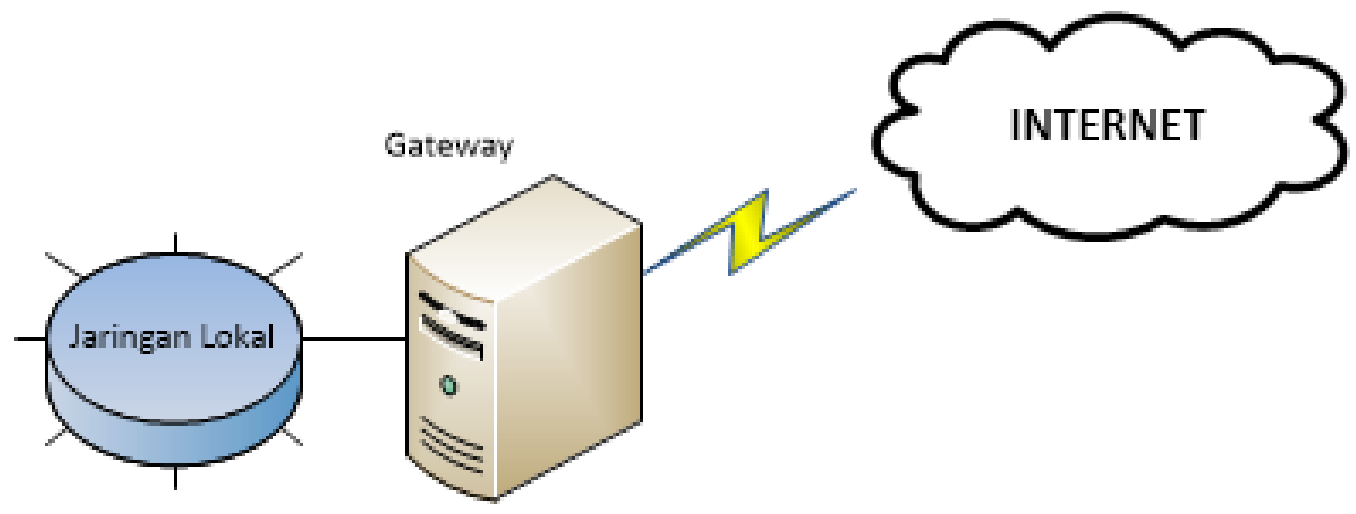

Gambar 1. Mekanisme NAT

\subsection{Kerio Control}

Perkembangan WinRoute bisa dikatakan lambat dibandingkan dengan aplikasi sejenis. Keberadaan WinRoute memang cukup memberikan alternatif sebagai aplikasi berkaitan dengan pemanfaatan jaringan internet, seperti internet sharing, proxy server NAT, dan sebagainya. Sejak versi 7, Kerio WinRoute namanya berubah namanya menjadi Kerio Control hingga saat ini. Aplikasi Kerio Control versi 7.4.1 yang digunakan di Puslit Bioteknologi menyediakan banyak roles dan features untuk pengaturan penggunaan jaringan internet, salah satu features yang digunakan adalah NAT. Dalam jaringan internet, Kerio Control bertindak sebagai router yang menerjemahkan source IP address (IP lokal) menjadi IP address yang berada dalam 1 subnet dengan network tujuan. Gambar 2 di bawah ini merupakan tampilan Kerio Control versi 7.4.1 server Pusat Bioteknologi. 




Gambar 2. Tampilan Kerio Control versi 7.4.1 Server Puslit Bioteknologi

\section{METODE}

Tahapan dari siklus hidup sistem ini, meliputi tahap perencanaan, tahap analisis, tahap perancangan, tahap implementasi, dan tahap penggunaan. Tahapan-tahapan tersebut dinamakan siklus hidup pengembangan sistem atau System Development Life Cycle (SDLC). Penelitian ini menggunakan siklus hidup pengembangan sistem, yang merupakan serangkaian aktivitas yang dilaksanakan oleh para profesional dan pemakai sistem informasi untuk mengembangkan dan mengimplementasikan sistem informasi. Sedangkan metode yang digunakan dalam penelitian ini, mencakup langkah-langkah dan kegiatan sebagaimana terlihat pada flowchart Gambar 3.

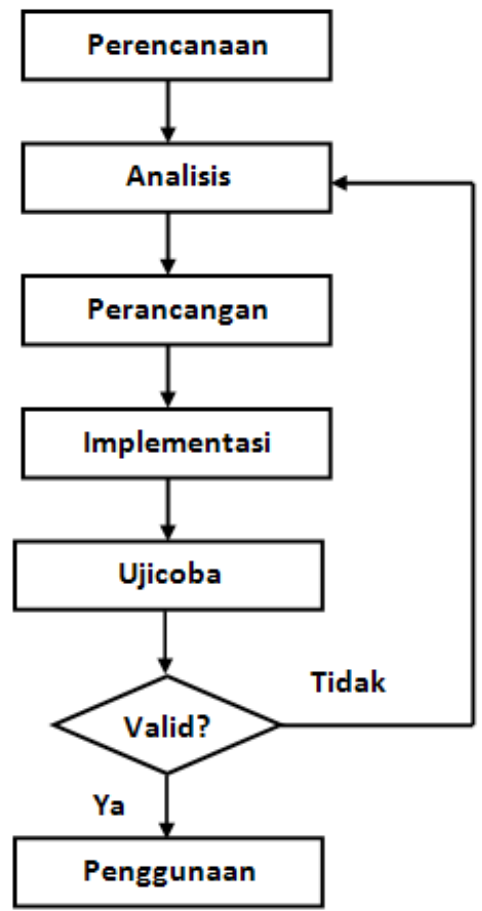

Gambar 3. Pendekatan System Development Life Cycle - SDLC (Jogianto, 1989) 


\section{HASIL DAN PEMBAHASAN}

Sebelum mengimplementasikan Kerio Control, jaringan komputer yang ada di Puslit Bioteknologi awalnya langsung terhubung ke Network Operation Center (NOC) yang ada di site Cibinong. Kemudian, dari NOC terhubung ke LIPI Jakarta melalui Fiber Optic (F/O). Seiring dengan perkembangan TI dan pengguna internet semakin banyak, diperlukan banyak IP untuk memenuhi kebutuhan pengguna di Puslit Bioteknologi. Dengan demikian, mulai direncanakan menggunakan Kerio Control sebagai proxy server sekaligus memanfaatkan beberapa roles dan feature yang ada di Kerio Control versi 7.4.1 dan feature NAT.

Tahapan selanjutnya adalah tahap analisis. Pada tahap analisis, penggunaan jaringan internet sudah menjadi kebutuhan untuk mencari data dan informasi yang berkaitan dengan penelitian, ketatausahaan, dan lain-lain. Puslit Bioteknologi mulai memanfaatkan mekanisme NAT karena dengan menggunakan IP yang ada tidak memungkinkan lagi dan tidak dapat memenuhi kebutuhan semua pengguna internet.

Sistem operasi yang digunakan dalam jaringan komputer (LAN) Puslit Bioteknologi adalah Windows Server 2008R2 dengan memanfaatkan Active Diretory Domain Services (ADDS). Dengan ADDS semua pengguna dibuat di server dan terjadi sinkronisasi antara Server ADDS dengan Server Kerio Control. Sedangkan untuk mendapatkan koneksi internet, LAN Puslit Bioteknologi harus mengakses jaringan yang ada di NOC LIPI Jakarta terlebih dahulu dengan menggunakan media F/O agar mendapatkan IP Public. Sedangkan topologi jaringan yang ada saat ini dijelaskan pada Gambar 4. Kerio Control digunakan sebagai proxy server dan aplikasi router yang berjalan di atas sistem operasi Windows Server 2012 dengan Kerio Control versi 7.4.1 yang sudah menyediakan NAT yang dibutuhkan jaringan LAN Puslit Bioteknologi. Gambar 4 di bawah ini merupakan perancangan cara kerja NAT di Puslit Bioteknologi.

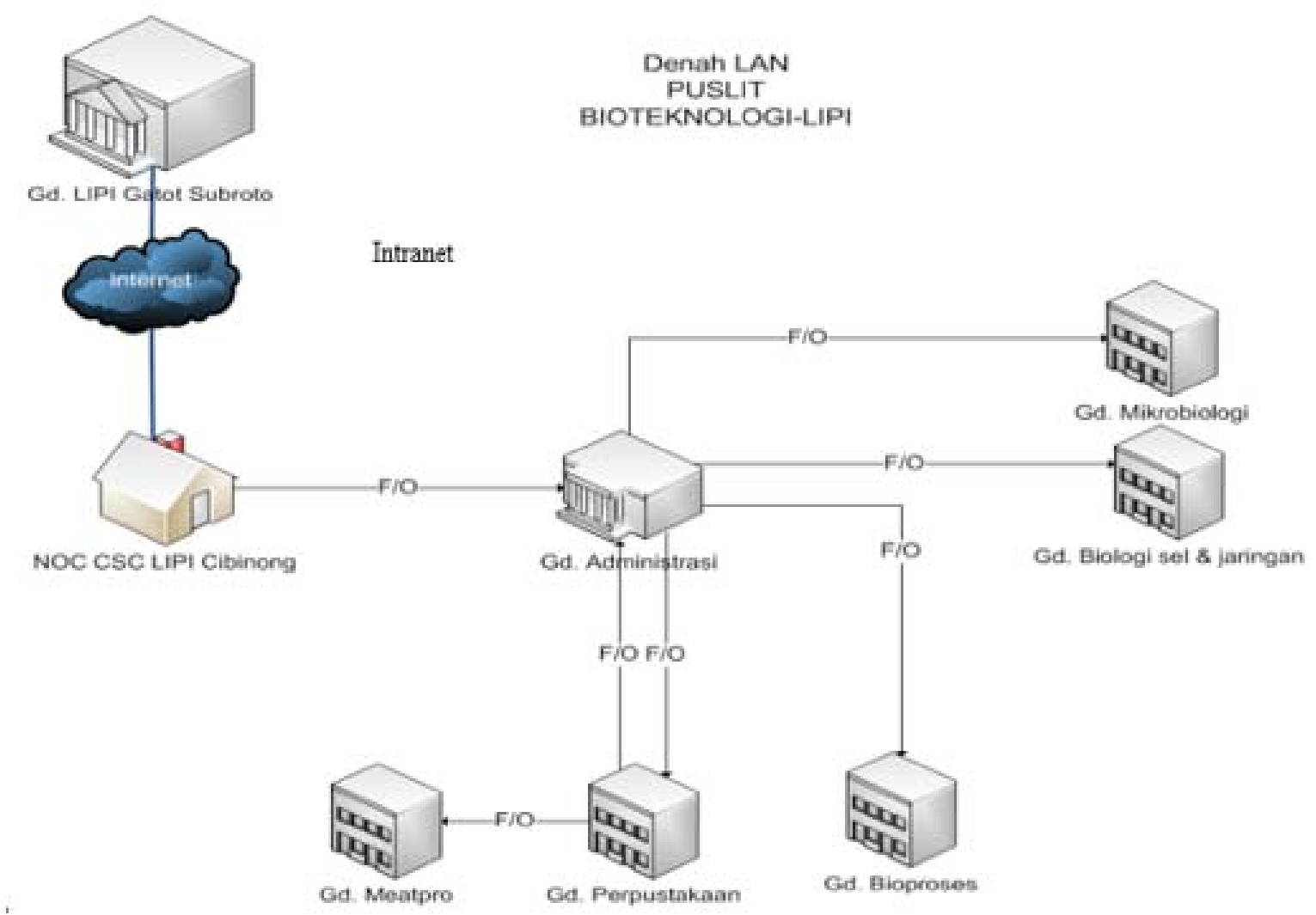

Gambar 4. Topologi jaringan Bioteknologi 
Jaringan LAN Puslit Bioteknologi terpasang di Gedung Administrasi, Gedung Mikrobiologi, Gedung Biologi Sel \& Jaringan, Gedung Bioproses, Gedung Meatpro, dan Gedung Perpustakaan. Sementara itu, ruang server atau NOC Puslit Bioteknologi ditempatkan di salah satu ruangan Gedung Perpustakaan serta Jaringan LAN terhubung dengan Jaringan LIPI Terpadu (JALITA) LIPI Jakarta.

Langkah awal menghubungkan jaringan LAN Puslit Bioteknologi adalah harus melewati gateway yang dengan IP 172.16.51.1 (sekaligus sebagai proxy server) dan menyambungkannya dengan jaringan NOC yang ada gedung Pusinov-LIPI Cibinong. Kemudian, NOC terhubung ke Jaringan LAN LIPI Jakarta dengan menggunaan network 192.168.51.0 dan gateway 192.168.51.1. Jaringan LAN LIPI Jakarta adalah gedung yang terhubung langung dengan ISP sehingga memiliki IP publik yang dapat digunakan oleh semua jaringan yang tergabung dengan jaringan LIPI. Setelah terhubung dengan jaringan JALITA, jaringan Puslit Bioteknologi dapat mengakses internet dengan IP publik yang diberikan oleh Internet Sevice Provider (ISP). IP publik yang diberikan dapat digunakan bersama-sama dengan pengguna dari setiap satuan kerja yang ada di lingkungan LIPI. Semua pengguna yang telah memiliki akun dan terdaftar di ADDS, kemudian disinkronisasi dengan Kerio Control sehingga pengguna secara otomatis ketika akan masuk ke jaringan internet harus menggunaikan akun (account) yang dibuat di ADDS Windows Server 2008R2 atau 2012 (Whittaker, 2012).

Di ADDS, pengguna harus memasukkan akun dan password yang telah dibuat melalui halaman web autentifikasi untuk mengkonfirmasi akun dan password yang dimiliki pengguna sehingga disahkan oleh NTLM atau login dari host yang sesuai. Setelah sukses diautentifikasi, pengguna ditentukan dalam aturan NAT kemudian diizinkan untuk mengakses layanan internet lainnya. Pengguna yang tidak ditentukan dalam aturan NAT akan menjadi batasan untuk mengakses situs web atau layanan internet lainnya (Ferschmannová, 2014). Gambar 5 di bawah ini merupakan contoh alur kerja NAT.

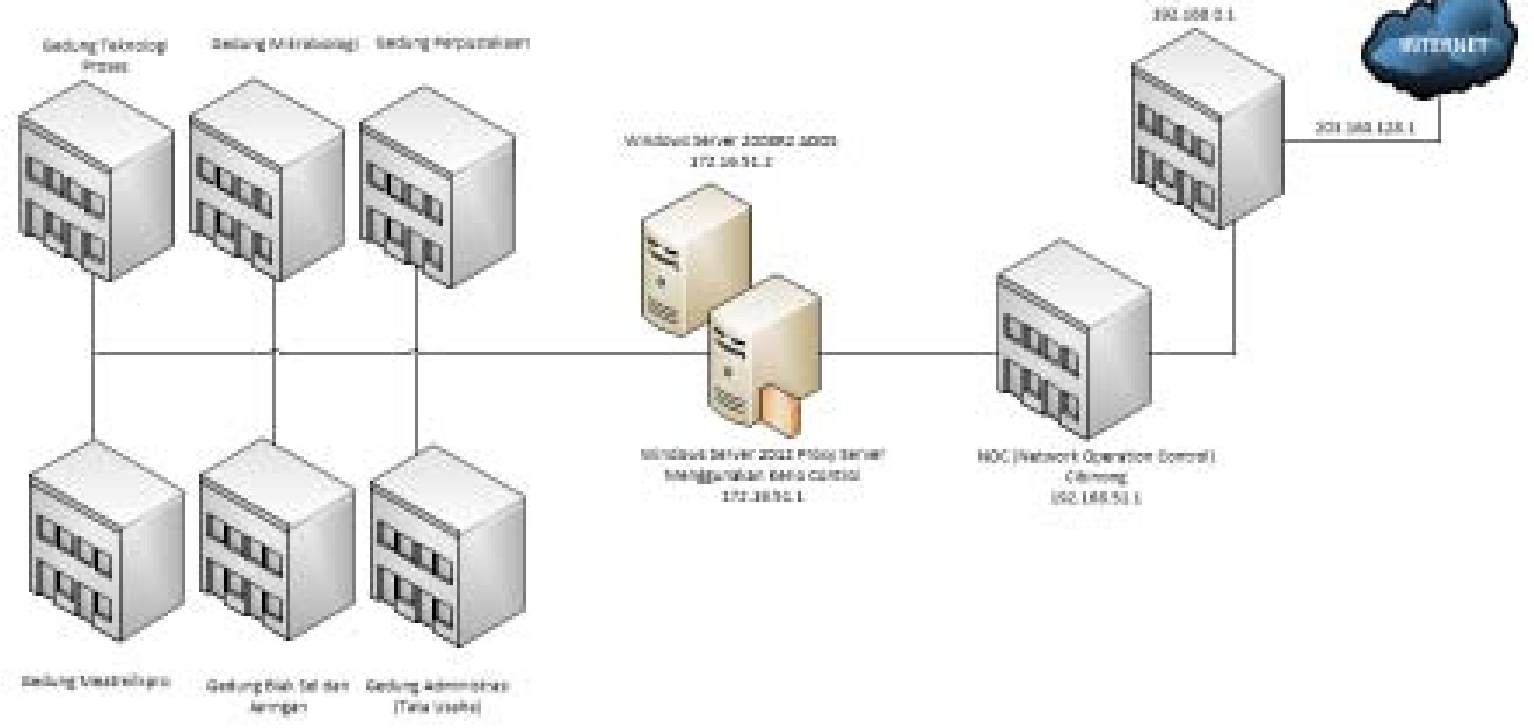

Gambar 5. Alur cara kerja NAT

Tahapan pertama dalam implementasi adalah melakukan instalasi Kerio Control 7.4.1 sebagai software yang digunakan untuk mengkonfigurasi proxy server dan NAT. Selanjutnya, konfigurasi proxy server dan NAT dimulai dengan mengatur interface pada Kerio Control. Gambar 6 di bawah ini merupakan contoh pengaturan interface pada Kerio Control. 


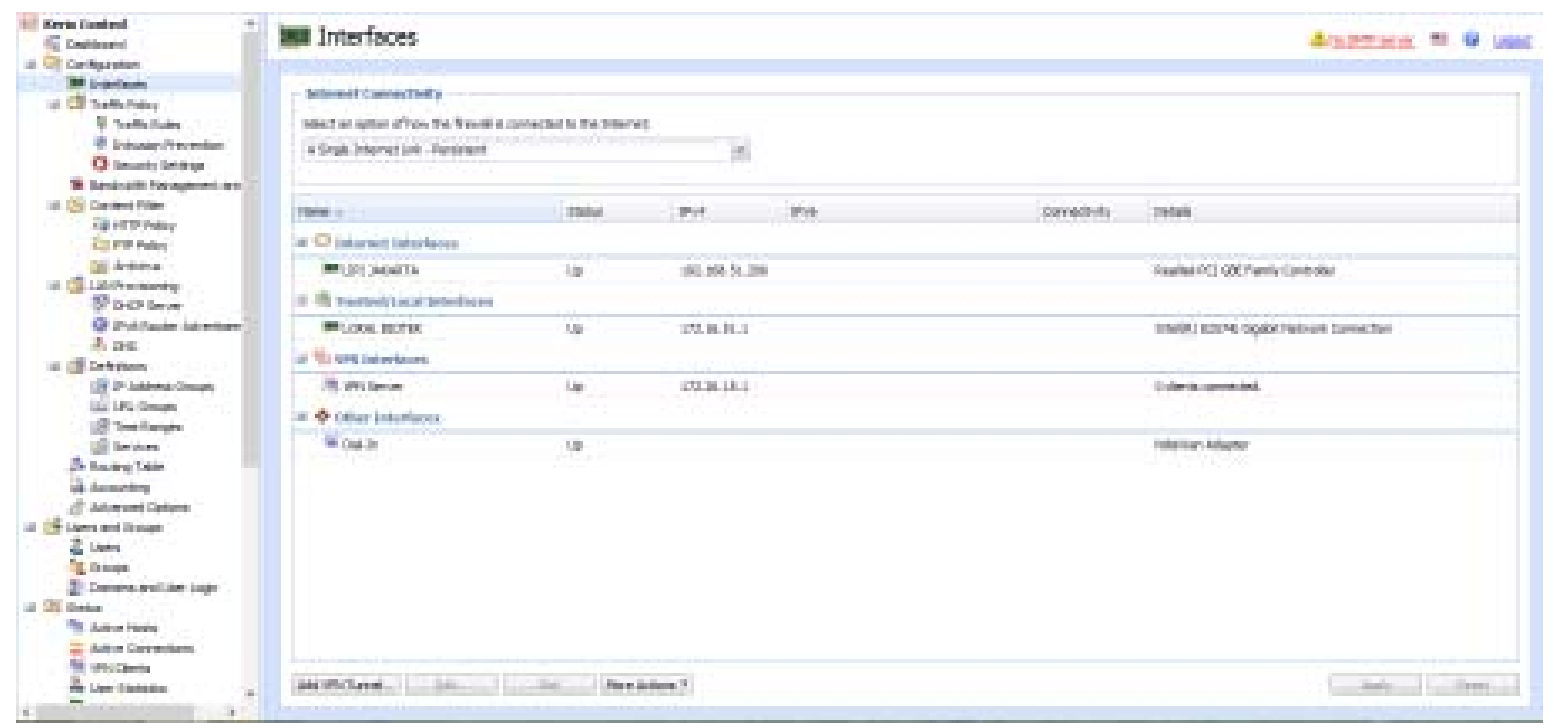

Gambar 6. Pengaturan interface pada Kerio Control

Pada komputer server yang digunakan untuk menginstalasi Kerio Control versi 7.4.1 dipasang dua kartu jaringan atau Network Interface Card (NIC) yang diperlukan pada interface. Ethernet pertama yang digunakan oleh internet interfaces dengan IP 192.168.51.206 telah menghubungkan LAN Puslit Bioteknologi ke NOC yang berada di Gedung Pusinov-LIPI Cibinong. Kemudian, dari NOC - CSC (Cibinong Science Center) langsung terhubung ke jaringan LIPI yang ada di LIPI Jakarta. Pada local interface digunakan NIC kedua yang berfungsi sebagai gateway dengan IP 172.16.51.1 dari LAN Puslit Bioteknologi.

Tahapan implementasi berikutnya adalah konfigurasi pada menu Traffic Rules. Pada menu Traffic Rules didaftarkan kebijakan NAT yang digunakan. Terdapat dua rules untuk fasilitas NAT, yaitu: 1) rules pertama didaftarkan dengan nama "Internet Access (NAT)", rules ini merupakan default dari Kerio Control dan pada saat dilakukan instalasi Kerio Control, rules tersebut telah terkonfigurasi secara otomatis pada saat software pertama kali digunakan; 2) rules kedua didaftarkan dengan nama "Internet access 2 (NAT)". Mengenai masing-masing konfigurasi rules pertama dan kedua ditampilkan pada Gambar 7 di bawah ini.

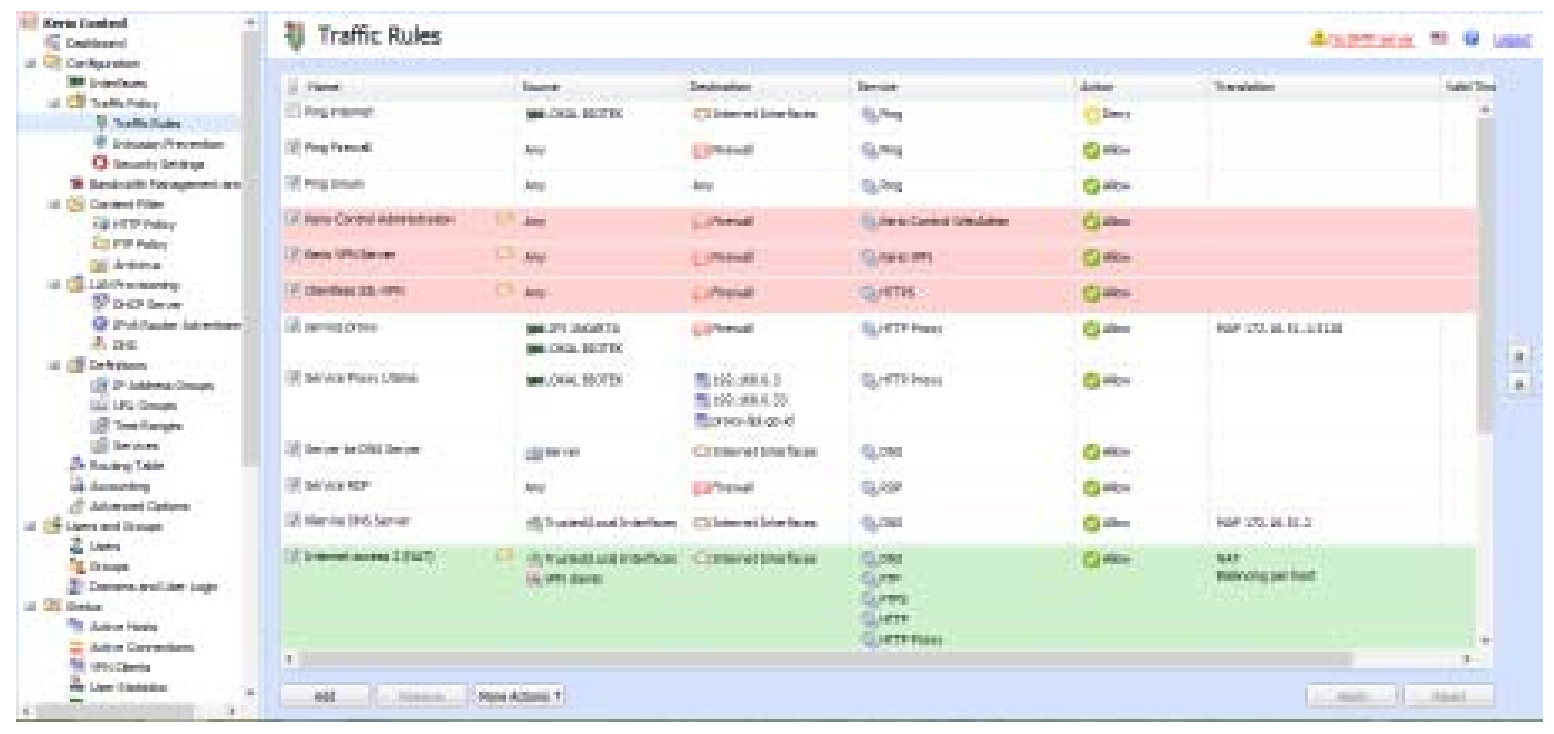

Gambar 7. Penerapan NAT pada menu Traffic Rules 
Pada rules pertama source diisi dengan Authenticated User. Authenticated User yang dimaksud adalah pengguna yang telah terdaftar ADDS Microsoft Windows Server 2008R2, kemudian disinkronisasi dengan Kerio Control versi 7.4.1. Pengguna yang telah terdaftar di Domain Control secara otomatis akan terhubung ke Kerio Control versi 7.4.1. Sementara itu, Destination pada Rules merujuk ke Internet Interface yang telah dikonfigurasi sebelumnya. Semua service digunakan dalam NAT di Puslit Bioteknologi. Terdapat tiga action pada konfigurasi NAT ini, yaitu Allow Deny dan Drop. Pada Rules translation di menu Traffic Rules diatur oleh NAT Balancing per host, di sini semua traffic dari setiap host dalam jaringan LAN akan di route ke internet link yang sama.

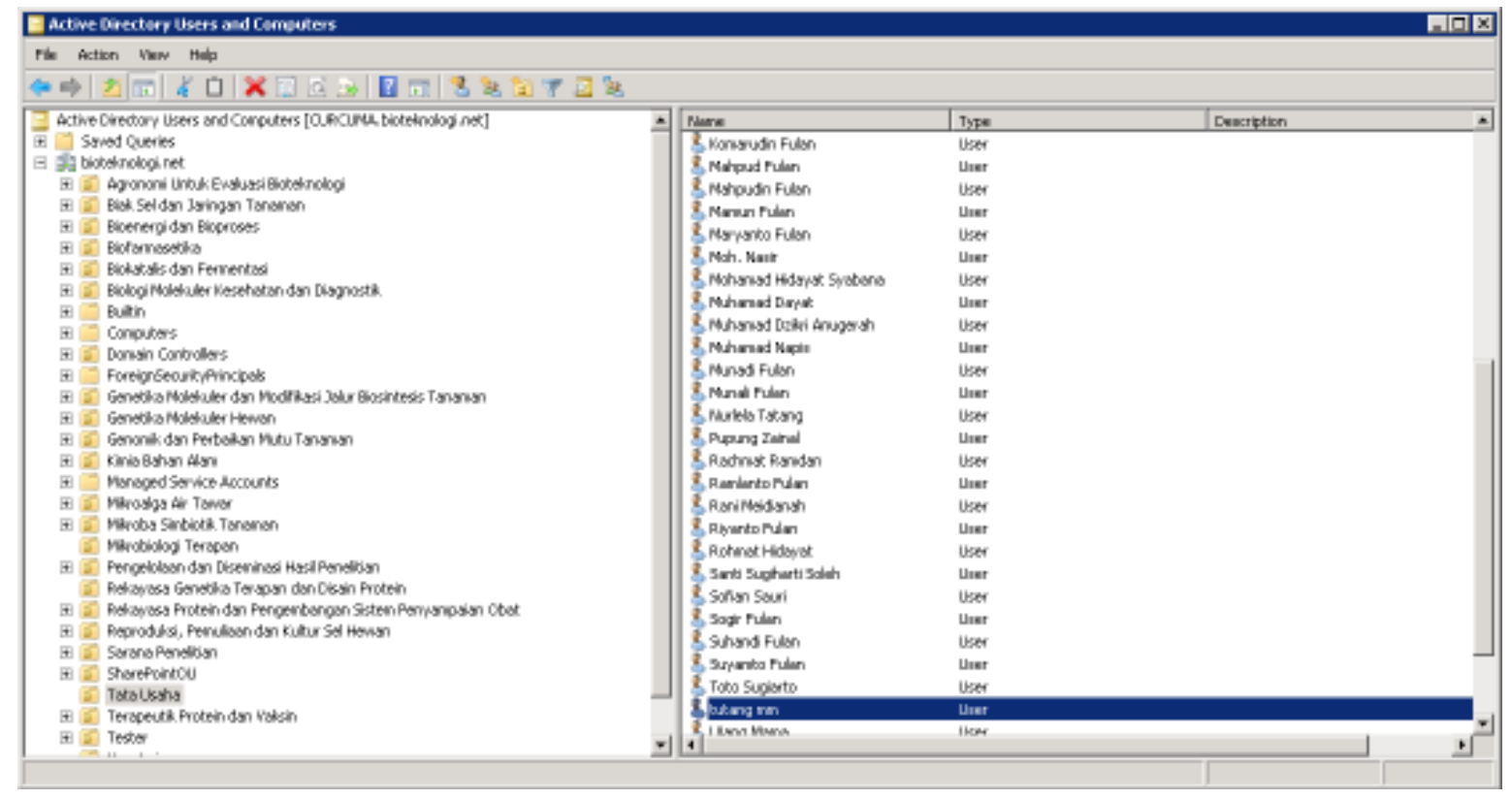

Gambar 8. Active Directory Users and Computers Windows Server 2008R2

Rules kedua hampir mempunyai konfigurasi yang pertama. Hal yang membedakan adalah pada source diisi Trusted/Local Interface. User yang masuk melalui jaringan hostspot atau WiFi akan menggunakan Rules ini untuk mendapatkan IP Public. Selain source, hal lain yang membedakan adalah service yang digunakan pada rules kedua.

Tahap pengujian bertujuan untuk mengecek kesesuaian hasil konfigurasi dengan alur perancangan yang dibuat, pengujian dilakukan untuk memastikan LAN Puslit Bioteknologi dalam mendapatkan IP publik untuk mengakses internet. Pengujian dapat terlihat ketika melakukan tracert untuk menunjukkan rute yang dilewati paket untuk mencapai tujuan. Langkah pengujian pertama adalah melakukan ipconfig pada salah satu user LAN Puslit Bioteknologi. Hasil dari ipconfig ditunjukkan pada Gambar 9 dan informasi yang ditunjukkan dengan menggunakan perintah ipconfig tersebut, diantaranya berupa default gateway, DHCP Server, dan DNS Server. 


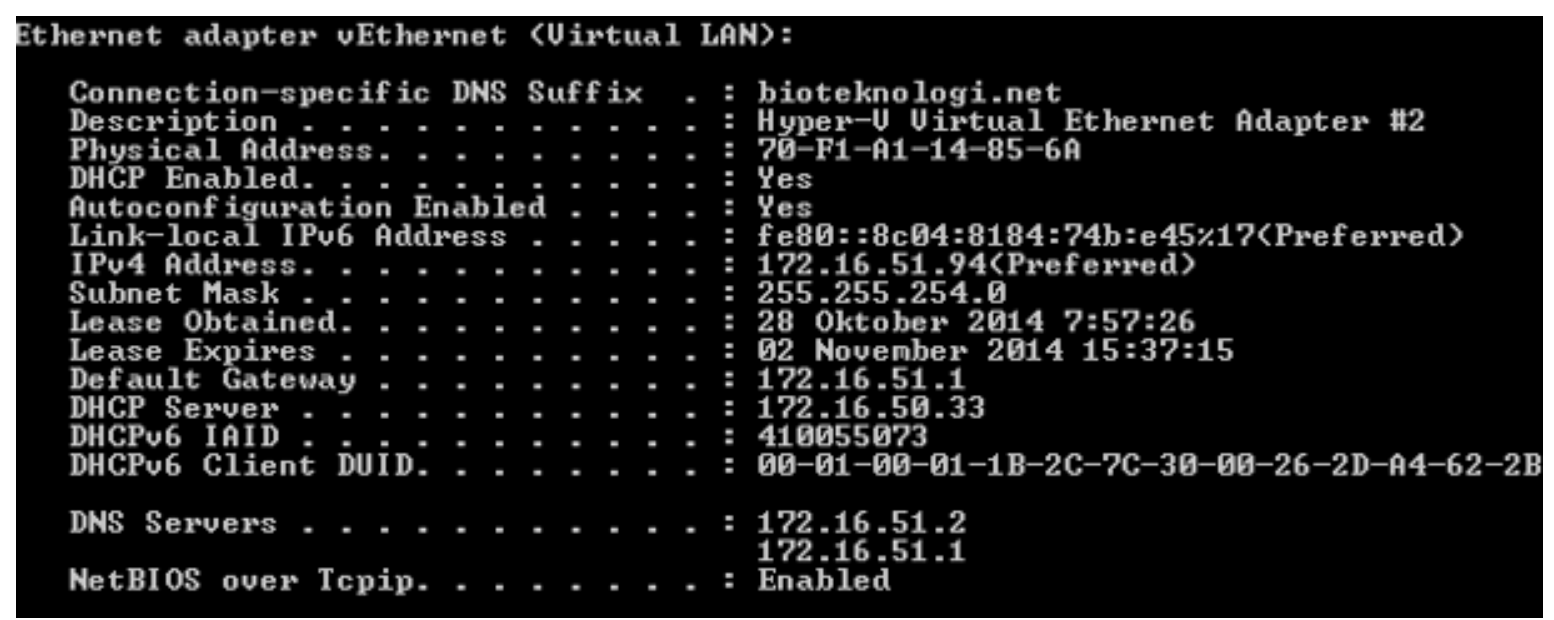

Gambar 9. Hasil ipconfig PC user di jaringan Puslit Bioteknologi

Langkah berikutnya, melakukan tracert pada www.lipi.co.id. Hasil tracert menunjukkan bahwa tujuan paket mempunyai IP 192.168.0.5, IP tujuan merupakan IP dari jaringan LIPI. Pada Gambar 10 dan Gambar 10 terlihat telah dilakukan translasi dari IP lokal di jaringan Puslit Bioteknologi dengan IP di jaringan LIPI. Paket terlebih dahulu melewati gateway dari jaringan lokal Puslit Bioteknologi yang memiliki IP 172.168.51.1. Setelah itu paket melewati gateway dari jaringan LIPI dan dilakukan translasi sehingga user dapat mengakses www.lipi.go.id. Hal ini sesuai dengan implementasi pada Kerio Control versi 7.4.1. ketika menjalankan fungsi dari NAT.

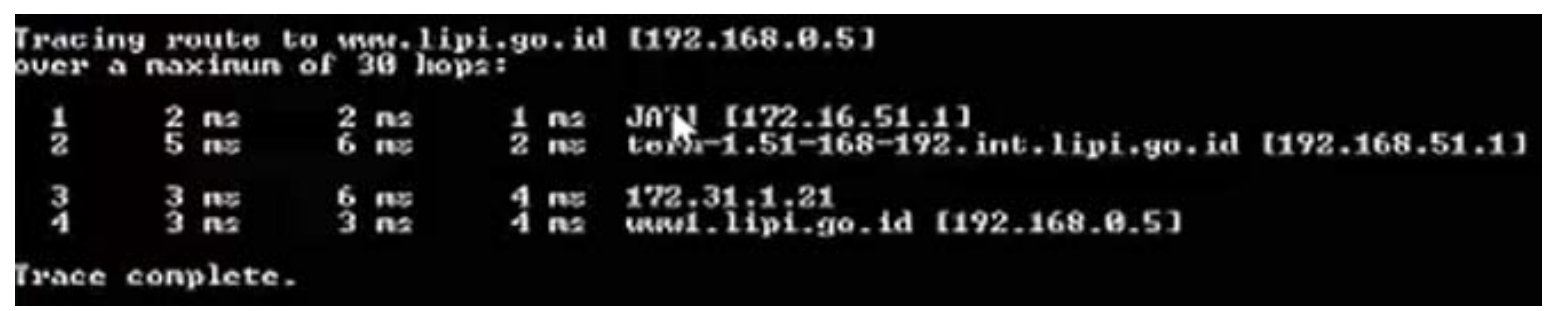

Gambar 10. Hasil tracert ke www.lipi.co.id

Pengujian selanjutnya adalah melakukan tracert ke alamat www.google.co.id menggunakan dari jaringan LAN di Puslit Bioteknologi. Melalui jaringan ini, pengguna akan mendapatkan IP publik untuk mengakses internet. Gambar 9 menjelaskan bahwa IP tujuan 74.125.128.94, paket akan diteruskan melalui gateway dari jaringan LAN Puslit Bioteknologi dan jaringan LIPI. Setelah itu, pengguna akan mendapatkan IP publik 203.168.128.1 agar dapat mengakses internet. Proses translasi untuk tahap ini dilakukan pada jaringan LIPI yang berhubungan langsung dengan Internet Service Provider (ISP). Kerio Control versi 7.4.1 digunakan sebagai gateway dari jaringan LAN Puslit Bioteknologi untuk terhubung dengan jaringan LIPI yang ada di NOC.

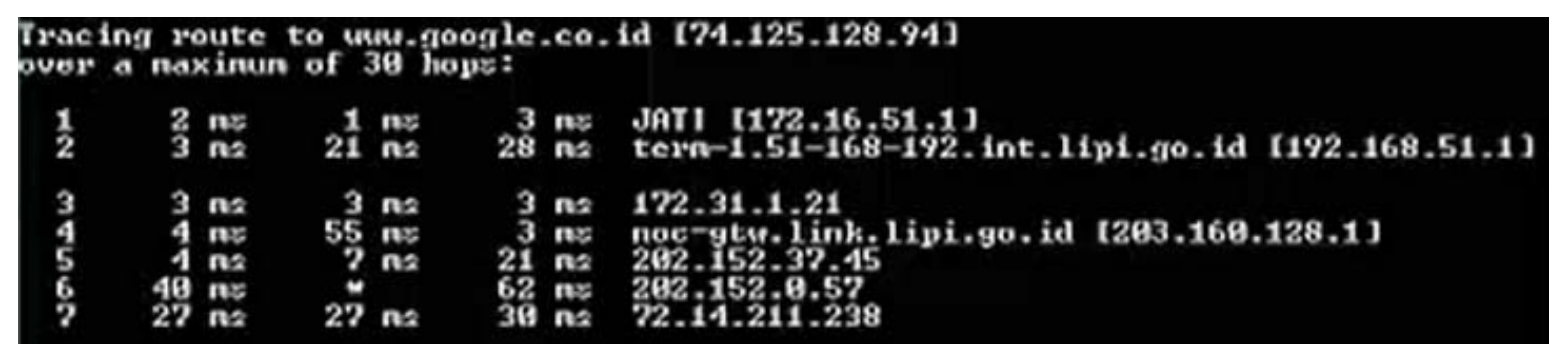

Gambar 11. Hasil tracert ke www.google.co.id 


\section{KEUNTUNGAN}

Dengan diterapkannya mekanisme NAT dan proxy server menggunakan Kerio Control versi 7.4.1, jaringan LAN di Puslit Bioteknologi semakin baik dan nyaman bagi peran pengguna, khususnya peneliti. Hal tersebut menunjukkan bahwa dengan kecanggihan NAT menggunakan Kerio Control versi 7.4.1. memberikan banyak manfaat bagi pengguna, khususnya mengurangi komplain pengguna. Penerapan NAT dengan Kerio Control 7.4.1 dapat mengoptimalkan bandwidth jaringan. Dalam hal ini, bandwith jaringan internet dapat difilter dan dibatasi waktu penggunaannya, seperti penggunaan youtube, download file, download film, dan mendengarkan musik. Adanya pembatasan tersebut, pengguna (peneliti) ketika mencari bahan penelitian/literatur dapat lebih leluasa tanpa harus dibatasi oleh kurangnya bandwidth.

Namun, penggunaan situs pada waktu tertentu juga dapat menghabiskan bandwidth Gambar 12 memberikan contoh pada pagi hari para pengguna jaringan khususnya yang menggunakan internet ternyata lebih dominan pada situs-situs tertentu , baik oleh peneliti maupun oleh pejabat fungsional lainnya.

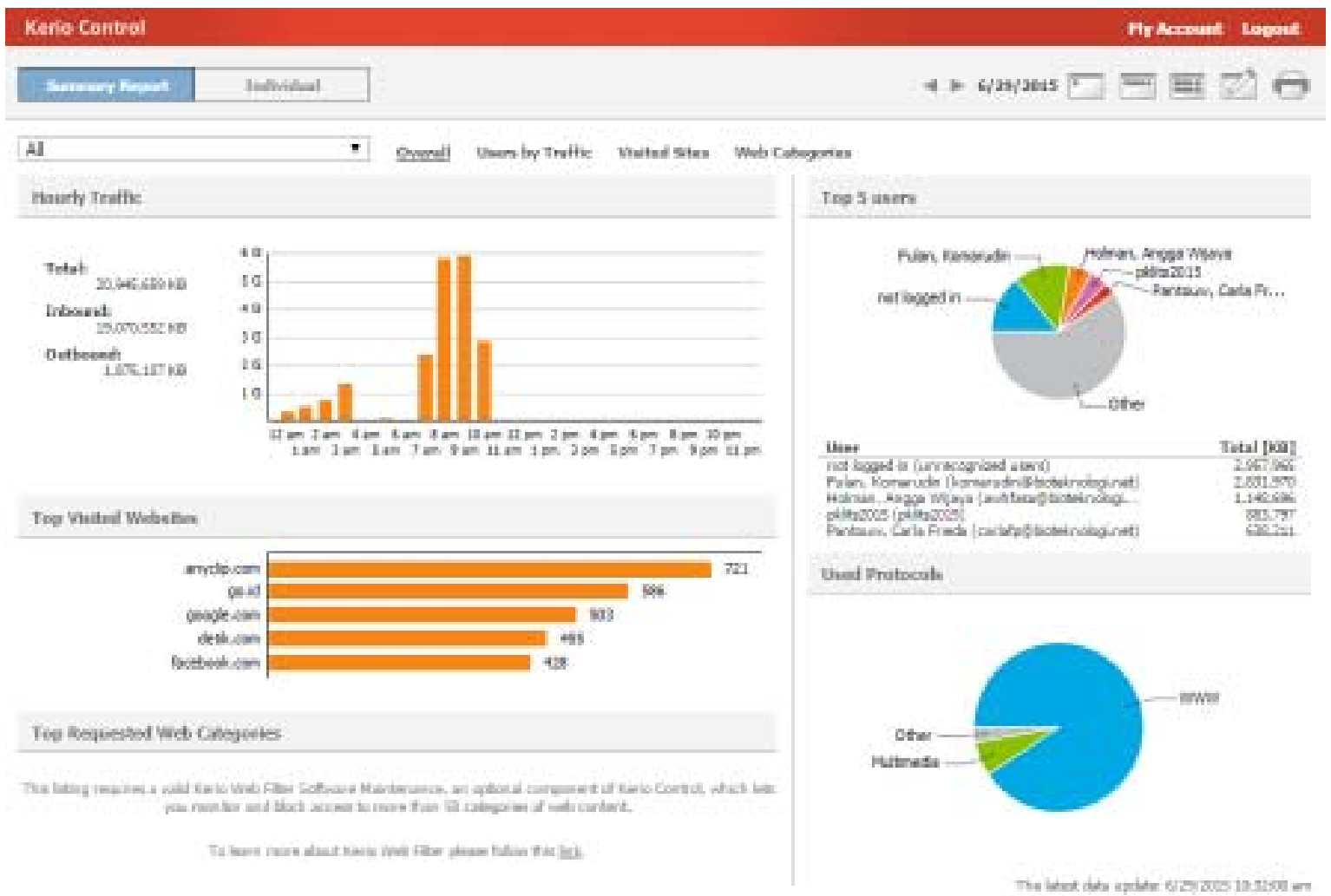

Gambar 12. Grafik penggunaan Kerio Control dan Top Visited Website

\section{KESIMPULAN}

Keterbatasan alamat IP lokal dapat menjadi masalah besar pada sebuah lembaga atau perusahaan yang berkemban. Hal tersebut terlihat jumlah alamat IP yang terbatas tidak sebanding dengan jumlah pengguna yang semakin bertambah. Pemanfaatan metode NAT menjadi solusi terbaik untuk mengatasi hal tersebut. Pemanfaatkan Kerio Control versi 7.4.1 yang memiliki servis (roles) NAT membantu semua pengguna melalui jaringan LAN di Puslit Bioteknologi untuk mendapatkan IP publik. Mekanisme 
NAT dapat membuat satu IP publik yang disediakan ISP untuk LIPI, dapat digunakan oleh banyak pengguna di setiap satuan kerja di lingkungan LIPI. Dengan peningkatan kualitas akses jaringan ini, diharapkan kinerja lembaga, peneliti, dan unsur pendukungnya dapat meningkat.

\section{DAFTAR PUSTAKA}

Ahmad, Nazrul M. and Asrul H. Yaacob. 2012. "IPSec over Heterogeneous IPv4 and IPv6 Networks: Issues and Implementation”. International Journal of Computer Networks \& Communications (IJCNC), Vol.4, No.5.

Babatunde, Olabenjo dan Omar Al-Debagy. 2014. "A Comparative Review of Internet Protocol Version 4 (IPv4) and Internet Protocol Version 6 (IPv6)". International Journal of Computer Trends and Technology (IJCTT), Vol. 13 No. 1. July.

Cohen, M.I. 2009. “Source Attribution for Network Address Translated Forensic Captures”. Digital Investigation, 5: 138 - 145.

Ferschmannová, Vendula. 2014. "Kerio Knowledge Base, Configuring Traffic Rules”. (http:// kb.kerio.com/product/kerio-control/security/configuring-traffic-rules-1312.html\#figruleuseraccessex2, diakses 17 Desember 2014).

Grang, Neha and and Anuj K.Gupta. 2013. "To Minimize the Consumption of Logical Addresses in a Network using OSPF with Overloading Technique”. Global Journal of Computer Science and Technology Network, Web \& Security, Vol. 13 Issue 11 Version 1.0.

Jogianto, H.M. 1989. Analisis dan Desain Sistem Informasi: Pendekatan Terstruktur Teori dan Praktek Aplikasi Bisnis. Yogyakarta: Andi Offset.

Masoud, Mohammad Z. M. 2013. “Analytical Modelling of Localized P2P Streaming Systems under NAT Consideration”. International Journal of Computer Networks \& Communications (IJCNC), Vol.5, No.3.

Rachman O dan Yugianto G. 2008. TCP/IP dalam Dunia Informatika \& Telekomunikasi. Bandung: Informatika Bandung.

Technologies, Kerio. 2012. "Kerio Control Administrator's Guide”. (http://manuals.kerio.com/control/ adminguide/en/, diakses 23 Desember 2014).

Whittaker, Ken. 2012. "How to Use a Windows Active Directory Group Policy Object (GPO) to Logon and logout Automatically Users from Kerio Control”. (http://kb.kerio.com/product/kerio-control/microsoft-active-directory-apple-open-directory/how-to-use-a-windows-active-directorygroup-policy-object-gpo-to-logon-and-logout-automatically-users-from-kerio-control917.html, diakses 23 Desember 2014).

Yao, Bing-Jhih; Shaw-Hwa Hwang, Cheng-Yu Yeh. 2014. "Mathematical Model of Network Address Translation Port Mapping”. ScienceDirect, AASRI Procedia, 8: 105 - 111.

Zhen-hua, WANG and YUAN Zhang-yi. 2010. "Research on Network Address Mapping Algorithm in IPv6 Private Network”. (http://www.sciencedirect.com/science/ journal/10058885, diakses 17 Desember 2014). 